\title{
The Plight of Swayne's Hartebeest
}

\author{
J. G. Lewis and R. T. Wilson
}

Swayne's hartebeest, a race found only in Ethiopia, has declined seriously in recent years, and there are now thought to be fewer than $\mathbf{7 0 0}$ left. The main population at Senkele - under $\mathbf{4 0 0}$ in May, 1976 - has to compete for grazing with the domestic animals of the Galla people $-13,000$ in the same month. Translocation experiments have not been successful, and the authors, who in late 1975 and 1976 made a study of the situation, believe that, while every effort to establish a reserve in the wild should be made, the threat of extinction is so great that a captive breeding group should be established immediately in a European or North American Zoo.

In recent years the number of Swayne's hartebeest Alcelaphus bucephalus swaynei has declined seriously, chiefly as a result of the introduction of mechanised agriculture at Senkele in southern Ethiopia, the area where they occur in greatest numbers, so that there is less space for both the hartebeest and the Galla pastoralists who use the area. It is now thought that there are fewer than 700 Swayne's hartebeest left in the whole of Ethiopia.

In 1974203 animals were caught at Senkele and translocated to the Awash National Park and the proposed Nachisar National Park, ${ }^{1}$ but unfortunately neither group settled down. In late 1975 and early 1976 we made a preliminary study of the hartebeest, mostly at Senkele, with visits to the Awash National Park, Maze River and Yavello. This report briefly outlines our findings and recommendations for the future conservation of Swayne's hartebeest.

The Senkele area is bounded on three sides by settlement and cultivation and on the fourth by a steep escarpment descending 400 metres (1300 ft) to the north-west shore of Lake Awasa. The hartebeest are confined to an area of approximately $59 \mathrm{sq} \mathrm{km}$, of which, during the study, they were using only $10 \mathrm{sq} \mathrm{km}$ of abandoned arable land that had been ploughed for three years

SWAYNE'S HARTEBEEST, showing characteristic horn formation and black coat-markings Melvin Bolton

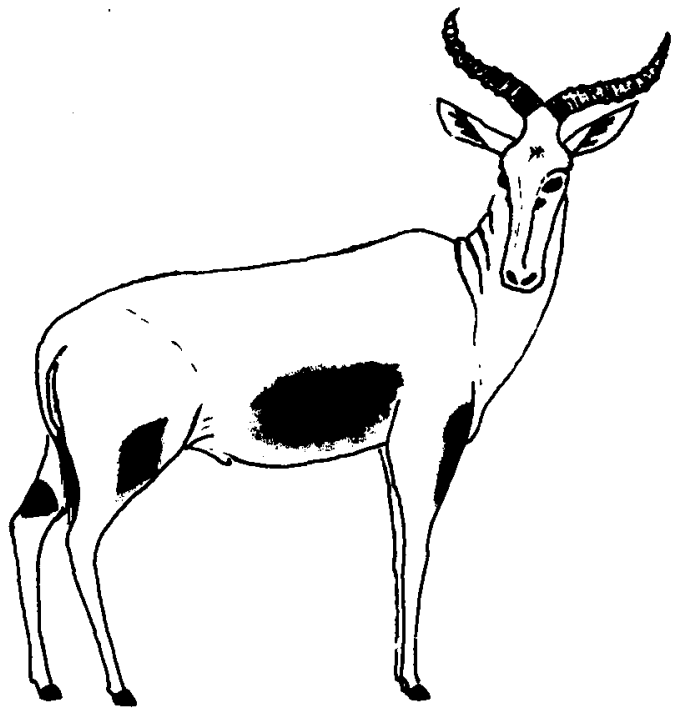


before being left fallow. (The number of years that land has been cultivated prior to being left fallow is an important factor in determining the subsequent regenerating vegetation, and, as most of the study area has at some time been cultivated, it is of importance in the grazing management.)

In August 1975 Stephenson ${ }^{4}$ counted 450 Swayne's hartebeest at Senkele and a further 260 at Siraro, an 8-sq-km area $20 \mathrm{~km}$ to the south. By December there were 440 at Senkele and only 19 at Siraro, but by May 1976 there were only 394 at Senkele and none at Siraro. Between October and February there are few domestic stock in the area due to lack of permanent water, but once the rains start in February numbers build up rapidly, and from February to October the Swayne's are dodging around herds of Galla cattle. In May 1976, 13,000 cattle were counted at Senkele. Until the recent and extensive spread of mechanised agriculture in the area it is probable that there was ample room for both livestock and hartebeest, but now the reduced space and poor quality of the grazing has forced the livestock and hartebeest into close contact and competition, to the detriment of the hartebeest.

In early December 1975, 69 per cent of the Senkele hartebeest were adults, with a male to female ratio of $1: 1.67 ; 14$ per cent were immatures and 17 per cent yearlings born at the beginning of the year. In May 1976, 74 per cent were adults and immatures, 11 per cent yearlings and 15 per cent calves. The hartebeest have a marked calving season which in 1975-76 began in the middle of December and continued until February. The highest percentage of adult females seen with calves at foot during the 1975-76 calving season was 59 per cent. By May only 40 per cent of the adult females had calves at foot, indicating a 32 per cent calf mortality rate between February and May. As large numbers of spotted hyaenas and common jackals were seen in the area in the calving season it is likely that the actual calving rate was somewhat higher than the figure obtained.

The good physical condition of the Senkele hartebeest shows that, despite the large numbers of domestic stock, they are able to make good use of the available grazing, and the period of about three months when there are no domestic stock enables them to build up their body reserves. They no longer visit the nearest water, some $15 \mathrm{~km}$ away, so probably they can get all the water they need from the vegetation.

The Galla, like the hartebeest, have lost a great deal of grazing in the Senkele area to mechanised agriculture, and they would be very reluctant to agree to any further reduction in order to create a reserve for the hartebeest. The recently created Farmers' Associations in the Senkele area have considerable authority and responsibility for the running of local affairs, and little can be achieved without their agreement. So some more practical means of conserving the hartebeest has to be found, and, as there are no long-term prospects for hartebeest at Senkele, it can only be a 'holding operation' until more suitable areas can be found.

The proposed Nachisar National Park, although not yet gazetted, contains 130 hartebeest, and also, like Senkele, large numbers of pastoralists and their stock. Even in the legally established Awash National Park, many Karryu pastoralists still live inside the park with their domestic animals, and there are only 12 hartebeest left despite the translocation of 90 to the park from Senkele in 1974. Until these areas can be firmly established as exclusively for wildlife the hartebeest cannot be secure. Neither Maze River, where there are 
over 100 hartebeest, nor Yavello, where numbers are estimated to be about 20 , have any legal status as wildlife areas, nor are any proposed, and the settlement around Maze River can be expected to increase; the hartebeest in the Yavello area probably suffer the least pressure from human activities because lack of permanent water and inter-tribal unrest has kept both human and livestock numbers low.

\section{Recommendations}

The situation is one of some urgency, with numbers low and still declining. The new Farmers' Associations are powerful, and little can be achieved without their consent; wildlife management plans have to show immediate benefit to the people, and, in the absence of any significant tourist trade, must be integrated with some acceptable form of rural development. Meanwhile, in view of the danger of this hartebeest becoming extinct in the wild, it is essential to capture a group of at least 20 animals for captive breeding in either Europe or North America where a number of zoos have the necessary experience. The Ethiopian Wildlife Conservation Organisation (WLCO) has already made preliminary approaches to several zoos. It might be necessary to take the animals from Nachisar not Senkele, for during the 1974 translocation operation from Senkele the local people, seeing the animals being taken away in trucks and not having been told why, assumed that they were being taken away to be eaten. Their resentment was such that it will require a lengthy education programme before any further translocation operations can be attempted at Senkele.

The Ministry of National Resources, which is responsible for running the state farms in the Senkele area, has proposed that some land be returned to the Galla pastoralists; it has also been suggested that some could be made available for the hartebeest. This might appear an ideal opportunity to establish a hartebeest reserve. Unfortunately, it is unlikely that the Galla would respect the boundaries of such a reserve, and, even if fenced, any efforts by the Ethiopian Wildlife Conservation Organisation (WLCO) to enforce the banning of livestock from the area would be strongly resisted by the Farmers' Associations. In the present situation, it is unlikely that the authorities could get the livestock and the people out. Of course, more grazing for the Galla at Senkele will immediately relieve the pressure on the hartebeest, and we have recommended that a range management project be set up, designed to improve the grazing for both the Galla livestock and the hartebeest, and also control livestock numbers and establish marketing systems. Guards for the hartebeest should be recruited from the local Farmers' Associations, for there is considerable resentment that the present WLCO game guards do not come from the Senkele area; as a result of threats and intimidation these guards are virtually ineffective. We have also recommended that WLCO should carry out an extensive education programme. The recommendations are a far cry from the ideal of establishing a reserve, but are thought to be the most practical in the present situation. WLCO has appointed a rural sociologist to spend several months at Senkele to study the best way to approach the implementation of the proposed developments, and FPS has made a financial contribution towards this. Without this background information no plans for conserving the hartebeest can hope to succeed.

For the long-term conservation of Swayne's hartebeest, Awash and Nachi- 
sar unfortunately have to be ruled out because of human activity. Of the two remaining areas, Maze River and Yavello, the latter appears to have considerable potential. The Ethiopian Livestock and Meat Board is planning extensive range management activities at Yavello, and the current levels of domestic stock are low. The area has no legal status as a wildlife sanctuary, but controlled management, even if based on livestock rather than wildlife, offers more security than any of the proposed or existing national parks.

The long-term survival of Swayne's hartebeest in their natural habitat depends very much on how much local people will cooperate. Cooperation will not be achieved by a purely authoritarian approach, although the establishment and enforcement of the law as it relates to wildlife is obviously a first priority. These people are not motivated by the esoteric justifications of wildlife conservation and in many cases are faced with problems of their own survival. The situation therefore requires a careful approach and the linking of wildlife conservation with suitable compensation based on development.

\section{References}

1. BERHANU, L. (1974) Operation Swayne's Hartebeest. Oryx, 12:556-558.

2. BOLTON, M. (1971) Ethiopia, last chance for Swayne's hartebeest. Biological Conservation, 3:2.

3. BOLTON, M. (1973) Hartebeest in Ethiopia. Oryx, 12:99-108.

4. STEPHENSON, J. G. (1975) An investigation into, with recommendations on, the status of Swayne's Hartebeest in the Shashamene area. Unpublished Report to the Ethiopian Wildlife Conservation Organisation, Addis Ababa.

J. G. Lewis and R. T. Wilson, Hunting Technical Services Ltd, Elstree Way, Boreham Wood, Herts.

\section{Protecting Migratory Animals}

Representatives of 45 countries and 11 international organisations met in Bonn last summer to consider IUCN'S draft for a Migratory Animals Convention. They agreed that the Convention should take the form of an 'umbrella' treaty for management and protection of migratory species worldwide, with supplementary agreements for particular aspects, regions, etc., and that a governing body, an advisory scientific council, and a secretariat would be needed. The majority opinion was that, while the most threatened species should have priority, all species should be covered. One effect of this would be that the shooting and trapping every year of vast numbers of migratory birds in some European countries, especially Mediterranean ones, would come within the Conventions remit (assuming their governments signed), thus reinforcing the efforts of those who have been battling for years, occasionally with some success, to get this stopped.

\section{Fish Farming}

A female cod produces from six million to ten million eggs. A few months later around 18 fry survive, and of these perhaps one or two can be expected to reach four years old and sexual maturity. But those millions of eggs provide a good case for fish farming. Professor Anton Skulberg, a Norwegian authority on fish conservation, has pointed out that the critical factor in the mortality rate of cod larvae is the availability of protein, i.e. plankton, immediately after hatching. While artificial rearing has been tried, it has never quite been possible to start-feed cod on a large scale; Professor Skulberg's solution would be to develop an artificial food from organic wastes, perhaps using algae to decompose sewage, feeding this product to zooplankton and feeding the zooplankton to the fish. This would also cut down on pollution, which is almost as great a threat to cod stocks as overfishing. 